\title{
KANTOR SEWA DAN CO-WORKING DENGAN PEMANFAATAN TAMAN ENERGI TERBARUKAN
}

\author{
Lidia Wiriani ${ }^{1)}$, Budi A. Sukada ${ }^{21}$ \\ 1)Program Studi S1 Arsitektur, Fakultas Teknik, Universitas Tarumanagara, lidiaawrn@gmail.com \\ 2) Program Studi S1 Arsitektur, Fakultas Teknik, Universitas Tarumanagara, budisukada@yahoo.com
}

\begin{abstract}
Abstrak
Seiring berjalannya waktu, saat ini maraknya pembangunan di kota metropolitan telah berdampak pada perubahan ekosistem, salah satunya yaitu isu lingkungan seperti keterbatasan ruang terbuka hijau (RTH). Saat ini Jakarta memiliki kawasan hijau hanya sekitar 9,8\% yang masih jauh dari 30\% sebagai standar ruang terbuka hijau di kota berdasarkan Undang-Undang No. 2 Tahun 2007. Selain itu, masalah lainnya di Jakarta adalah meningkatnya pemakaian listrik perkantoran yang umumnya dikarenakan adanya peningkatan kebutuhan ruang usaha di dunia bisnis dan industri kreatif (start-up) yang sedang berkembang pesat. Pembangunan di kota seringkali hanya berpusat pada kebutuhan manusia akan ruang dan fasilitasnya, sementara disisi lain kurang memperhatikan dampaknya terhadap lingkungan sekitar. Adapun proyek pada tugas akhir ini adalah untuk mengajukan suatu rancangan pembangunan kantor sewa dan co-working dengan pemanfaatan taman energi terbarukan agar tercipta kelistrikan yang lebih efisien, serta perwujudan ruang terbuka hijau yang luas sebagai ciri bangunan ekologis, sehingga diharapkan dapat memberikan kontribusi untuk perbaikan lingkungan. Paradigma utama dalam mendesain proyek ini adalah bagaimana menciptakan enviromental balance dengan pendekatan ecosystem environment dan energy efficiency. Adapun pendekatan metode yang digunakan sebagai acuan adalah standar Leadership in Energy and Environmental Design (LEED). Proyek ini disamping menyediakan sarana perkantoran, juga menawarkan fasilitas yang multifungsi seperti coffeeshop, minimarket, food court, toko buku dan alat tulis, fitness center, fun games area, jogging track, lapangan basket, serta gerai ATM. Sementara untuk area ruang terbuka hijau (RTH) tersedia taman energi terbarukan (renewable energy park) yaitu bioo panel garden, kolam irigasi, dan area taman pohon.
\end{abstract}

Kata kunci: Ruang terbuka hijau (RTH); kebutuhan listrik; kantor sewa dan co-working; taman energi terbarukan

\begin{abstract}
As time goes by, currently the development growth in metropolitan cities has been leading to the ecosystem change, one of which is the decrease of the green open space (GOS). Nowdays Jakarta has only 9.8\% green area and rather it is still far from $30 \%$ as a standard of green open space according to government's Law No. 2 of 2007. In addition, another problem in Jakarta is the increase on the office electricity needs that generally due to the growth of office space demands in business and industrial, including start-up sectors that currently growing fastly. Development in cities is very often only focused on human interests on spaces and facilities, meanwhile on the other side, it just pay less attention to the surrounding environmenta impact. Therefore, this final project is promptly proposing a design and construction of a rental office and co-working office with the use of renewable energy park and solar energy with the aim of creating a more efficient electricity and also to provide a spacious green open spaces as charasteristic of an ecological building, to enable to promote a positive contribution to environmental improvement. The method approach used as reference in this project is the Leadership in Energy and Environmental Design (LEED) standard. This project will not only offer office facilities but also a multifunctional facilities such as coffee shop, mini market, food court, book and stationery store, fitness center, fun games area, jogging track, basketball court, and ATM corner, while for green open space
\end{abstract}


(GOS) there is also renewable energy park, namely bioo panel garden, irrigation ponds, and tree areas.

Keywords: Green office space (GOS); electricity consumption; rental and co-working office; renewable energy park

\section{PENDAHULUAN}

\section{Latar Belakang}

Seiring berjalannya waktu saat ini, maraknya pembangunan di kota metropolitan telah memberikan dampak pada perubahan ekosistem, salah satunya yaitu isu lingkungan seperti keterbatasan ruang terbuka hijau (RTH). Pada dasarnya lahan hijau di Jakarta cukup banyak namun tidak dimanfaatkan dengan baik, seperti adanya permukiman liar atau fasilitas-fasilitas yang sudah mati dan terbengkalai sehingga tidak ada gunanya bagi kehidupan ekosistem. Selain itu, masalah di Jakarta lainnya adalah meningkatnya pemakaian listrik perkantoran yang umumnya terjadi karena peningkatan kebutuhan ruang usaha di dunia bisnis dan industri kreatif (start-up) yang saat ini semakin berkembang pesat. Pembangunan di kota seringkali hanya berpusat pada kebutuhan manusia akan ruang dan fasilitasnya, sementara disisi lain kurang memperhatikan dampaknya terhadap lingkungan sekitar.

Dilansir dari liputan6.com, Jakarta dengan luas kawasan 661,5 kilometer persegi setidaknya harus memiliki kawasan hijau 200 kilometer persegi namun kenyataannya hanya 9,8\% dan masih jauh dari $30 \%$ sebagai standar ruang terbuka hijau di kota berdasarkan Undang-Undang No. 2 Tahun 2007. Sejak April 2013, Pergub DKI Jakarta juga telah mewajibkan bangunan di Jakarta memenuhi persyaratan bangunan ramah lingkungan, namun hingga saat itu masih banyak pengembang yang belum perhatian terhadap hal tersebut sehingga Jakarta termasuk daerah yang mengkonsumsi energi terbanyak di Indonesia. Maka dari itu, masalah diatas merupakan hal yang penting dan perlu untuk diteliti, karena dibutuhkan perancangan arsitektur dengan pendekatan ekologi seperti optimalisasi RTH dan efisiensi energi dalam pembangunan perkantoran di Jakarta.

\section{Rumusan Permasalahan}

Manusia semakin tidak bijaksana dalam memanfaatkan alam sehingga menimbulkan efek buruk terhadap lingkungan, salah satunya adalah semakin berkurangnya ruang terbuka hijau (RTH). Pada dasarnya, manfaat RTH untuk menjaga dan menyeimbangkan kondisi lingkungan atau ekosistem sekitarnya, namun pembangunan di kota seringkali hanya berpusat pada kepentingan manusianya saja, tidak memikirkan dampaknya terhadap ekosistem sekitar. Masalah lainnya adalah pemakaian listrik pada perkantoran yang tidak memperhitungkan penggunaannya. Kedua masalah tersebut sering diperbincangkan di berbagai kalangan dunia khususnya di kotakota besar. Sehingga menarik untuk diteliti karena kota membutuhkan peran arsitektur sebagai perwujudan bangunan ekologi dengan optimalisasi RTH dan efisiensi energi, yang selanjutnya diharapkan dapat memberikan kontribusi untuk perbaikan lingkungan.

\section{Tujuan}

Tujuan proyek ini secara umum untuk menciptakan sebuah tipologi baru ibukota agar beralih menuju pembangunan perkantoran yang berbasis ekologi dan ramah lingkungan untuk memberikan kontribusi pada perbaikan lingkungan dan kualitas energi di perkotaan. Tujuan khususnya adalah menciptakan kelistrikan yang lebih efisien pada kantor sewa dan co-working dari pemanfaatan ruang terbuka hijau yang mendominasi dari luas keseluruhan tapak, sehingga antara kehidupan manusia dan lingkungan dapat saling berdampingan dan seimbang. 


\section{KAJIAN LITERATUR}

\section{Ekologi Arsitektur}

Ekologi berasal dari bahasa Yunani 'oikos' dan 'logos'. Oikos berarti rumah tangga atau habitat atau tempat tinggal, dan logos berarti ilmu atau bersifat ilmiah. Ekologi didefinisikan sebagai ilmu yang mempelajari tentang hubungan timbal balik antara makhluk hidup dengan lingkungan di sekitarnya. Istilah ekologi pertama kali dikemukakan oleh Ernst Haeckel (1834-1914). Ekologi arsitektur mengandung dimensi waktu, alam, sosio kultural, ruang dan teknik bangunan. Bersifat kompleks, mengandung bagian-bagian arsitektur biologis (kemanusiaan dan kesehatan), serta biologi pembangunan (Frick, 1998).

\section{Beyond Ecology (Melampaui Ekologi)}

Arsitek yang "melampaui" ekologi adalah sebuah cara tentang bagaimana arsitektur menampilkan kualitas spasial dengan menempatkan posisi kompleksitas dan keunikan dari kondisi ekosistem yang ada di sekitarnya. Berikut definisi beyond ecology (melampaui ekologi) berdasarkan Virtual Seminar Stupa 8.31:

Menurut Winata (2021), beyond ecology berbicara tentang sistem yang saling terhubung, ketergantungan, dan berinteraksi antara komponen biotik dan abiotik. Beyond ecology adalah suatu sistem biologi yang digunakan untuk memelihara atau menyelesaikan fenomena nonbiologi. Dengan adanya hubungan komunikasi dari segi material, energi dan informasi yang saling meramu dan terkoneksi, maka dapat memberi dampak positif bagi kesejahteraan hidup manusia ataupun tumbuhan dan binatang.

Menurut Sutanto (2021), beyond ecology dikaitkan dengan dromos: berlari cepat dan oikos: rumah. Diartikan sebagai kondisi ekosistem dengan kondisi formasi sosialnya mengalami percepatan dan kecepatan. Fenomena kecepatan ini menjadi jantung dunia keseharian saat ini. Ekosistem disekitar kita mengalami pemadatan waktu (time compression) sebagai konsekuensi dari percepatan kehidupan.

\section{Ruang Terbuka Hijau (RTH)}

\section{Pengertian}

Menurut Undang-Undang No. 26 Tahun 2007 tentang Penataan Ruang, yang dimaksud dengan ruang terbuka hijau (RTH) adalah area memanjang atau jalur atau mengelompok yang penggunaannya lebih bersifat terbuka, tempat tumbuh tanaman, baik yang tumbuh secara alamiah maupun yang sengaja ditanam. Kawasan ini didominasi oleh vegetasi baik itu pepohonan, semak, rumput-rumputan, serta vegetasi penutup tanah lainnya.

\section{Fungsi dan Manfaat}

Berikut adalah berbagai penjelasan mengenai fungsi dan manfaat dari ruang terbuka hijau (RTH):

a. Fungsi utama (intrinsik) yaitu memberi jaminan pengadaan RTH menjadi bagian dari sistem sirkulasi udara (paru-paru kota).

b. Fungsi tambahan (ekstrinsik) yaitu:

- Fungsi ekologis, meningkatkan kualitas lingkungan seperti peningkatan kualitas air tanah, menurunkan peluang terjadinya banjir, mengurangi polusi udara, dan memiliki peran dalam pengaturan iklim mikro.

- Fungsi sosial budaya, memberikan fungsi sosial budaya bagi masyarakat. Area ini dapat menjadi tempat atau ruang dalam kegiatan interaksi sosial, penanda kawasan, hingga untuk penelitian dan pendidikan.

- Fungsi ekonomi, meningkatkan daya tarik bagi masyarakat, wisatawan lokal, hingga wisatawan asing untuk berkunjung.

- Fungsi estetika, perencanaan dan penataan yang sudah dilakukan dengan baik tentu saja tidak menghiraukan sisi keindahan yang akan ditunjukkan dari area ini. 


\section{Jenis-jenis Ruang Terbuka Hijau}

Secara spesifik, bentuk ruang terbuka hijau terdiri dari beberapa bentuk, antara lain:

a. Taman kota, ruang di dalam kota yang strukturnya bersifat alami dengan sedikit bagian yang terbangun. Taman ini berisi beraneka pepohonan dan sering juga terdapat lahan terbuka yang luas sebagai tempat aktivitas olah raga dan aktivitas lainnya.

b. Taman rekreasi, untuk kegiatan yang cukup aktif seperti piknik, olahraga, dan permainan melalui penyediaan sarana-sarana pendukung lainnya.

c. Lapangan terbuka umum: sebagai wadah kegiatan olahraga, tempat pertemuan terbuka dan menjadi penunjang kualitas lingkungan.

d. Pemakaman dan monumen, biasanya lahannya tidak terlalu luas dan lahan sisanya di tanami oleh berbagai jenis pohon baik untuk lasan sejarah, pendidikan maupun keindahan.

e. Jalur hijau dan median jalan, pepohonan yang ditanam disamping kiri-kanan sepanjang jalan atau jalur pergerakan yang berfungsi sebagai penyegar udara kota.

f. Halaman gedung atau pekarangan, halaman gedung merupakan lahan dari persil yang tidak terbangun, biasanya terdapat pada bangunan-bangunan seperti sekolah, kantor polisi, mall dan lain-lain. Kadang-kadang halaman gedung dapat digunakan sebagai taman pasif.

g. Sempadan, ruang terbuka hijau yang berfungsi sebagai batas dari sungai, danau dan jalur rel kereta api atau bahkan kawasan limitasi terhadap penggunaan lahan disekitar.

h. Kawasan khusus, kawasan khusus adalah kawasan lainnya yang berupa ruang terbuka hijau tetapi tidak diklasifikasikan sebagai taman ataupun jenis ruang terbuka lainnya.

\section{Kantor Sewa}

\section{Pengertian}

Menurut Marlina (2008), kantor sewa adalah suatu bangunan yang mewadahi transaksi bisnis dan pelayanan secara profesional. Ruang-ruang dalamnya terdiri dari ruang-ruang dengan fungsi yang sama, yaitu fungsi kantor dengan fasilitas pemakai sebagai penyewa atas ruang yang digunakannya.

\section{Sistem Penyewaan Ruang}

a. Sistem areal terbuka (open area tenant)

- Pengertian: ruang hanya merupakan ruang-ruang terbuka dimana dalam pembagiannya nanti tergantung besar kecilnya kebutuhan ruang dari penyewa.

- Keuntungan: penyewa tidak dibatasi dalam hal ini kebutuhan atau menentukan luas lantai yang dibutuhkan serta dalam pengaturan ruangnya. Pemasangan dinding atau partisi ditanggung oleh penyewa. Tata ruang lebih fleksibel.

- Kerugian: karena tidak ada pembatasan, maka kesulitan akan muncul pada pola distribusi ruang dan kemungkinan reorganisasi sehubungan dengan habisnya masa kontrak atau ganti penyewa.

b. Sistem areal terbagi-bagi (partial area tenant)

- Pengertian: sistem pembagian ruang yang sudah membagi-bagi suatu ruang besar dalam satu lantai ke bentuk yang lebih kecil.

- Keuntungan: bagi perusahaan tingkat sedang dalam arti jumlah personilnya, akan lebih banyak kemungkinan menyewa karena standar harga sewanya lebih murah dibandingkan dengan sistem "open area tenant". Kemungkinan untuk penerapan sistem ini pada bangunan berlantai lebih dari 4 lantai.

- Kerugian: untuk perusahaan yang lebih besar dan membutuhkan luas lantai yang besar akan kurang diminati karena merasa terlalu dibatasi.

c. Gabungan sistem area terbuka dan sistem area terbagi

Sistem ini merupakan pengurangan kerugian-kerugian dengan kedua sistem yang telah diuraikan di atas. Secara umum tipe semacam ini biasanya membagi peruntukan areanya, 
misalnya: 1-5 digunakan sistem area terbuka, sedangkan lantai selanjutnya memakai sistem area terbagi.

\section{Jangka Waktu Sewa Ruang}

Jangka waktu sewa kontrak pada kantor sewa diatur dan ditentukan pemilik/pengelola bangunan dengan persetujuan pihak penyewa atau pemakai. Jangka waktu sewa kontrak dapat diklasifikasikan sebagai berikut:

a. Sewa jangka panjang, ditetapkan oleh pihak properti yang biasanya mempunyai jangka waktu sewa tahunan.

b. Sewa jangka pendek, ditetapkan oleh pihak properti dengan jangka waktu per beberapa bulan sesuai perjanjian kontrak sewa dengan pihak penyewa.

\section{Luas Unit yang Disewakan}

Dalam sistem penyewaan ruang kantor sewa berdasarkan luas unit ruang, dapat diklasifikasikan sebagai berikut:

a. Berdasarkan satuan unit ruang terkecil yang ditetapkan oleh pemilik bangunan.

b. Berdasarkan pada kelipatan unit ruang terkecil.

c. Berdasarkan sewa per lantai.

\section{Kantor Co-working}

\section{Pengertian}

Jenis kantor co-working adalah jenis kantor yang disewakan dengan sistem berbagi kantor, mengedepankan konsep sharing atau berbagi oleh para pekerja dengan gaya komunal/modern. Dalam artinya, satu ruangan kantor dapat ditempati oleh beberapa perusahaan dengan jenis bisnis yang berbeda.

\section{Keuntungan}

a. Biaya sewa yang lebih murah dibandingkan sewa ruang kerja tetap di gedung perkantoran yang relatif mahal.

b. Memberikan kemudahan bagi entrepreneur muda dan start-up tanpa rasa khawatir mengatur dan membangun kantor mereka.

c. Fasilitas meeting room disediakan untuk para penyewa co-working. Dengan begitu dapat bertemu klien di lingkungan professional yang akan menambah kepercayaan klien.

d. Memiliki kesempatan untuk membangun koneksi dan kolaborasi dengan pemilik usaha kecil lainnya.

e. Sangat fleksibel dan tidak terpaku pada aturan layaknya kantor konvensional.

\section{Kekurangan}

a. Privasi bukanlah prioritas utama di co-working space.

b. Di co-working tidak dapat memiliki kendali atas pertemuan perusahaan lain, volume orang yang berbicara di telepon, atau seseorang di meja sebelah yang mendengarkan musik, harus siap menghadapi gangguan potensial yang tidak dapat dikendalikan.

c. Kurang bebas. Kemungkinan besar tidak dapat menghiasi dinding, meninggalkan barang atau membawa kursi meja favorit. Pekerja juga harus berurusan dengan pembatas ruang dengan orang lain.

\section{METODE}

Metode penelitian menggunakan metode deskriptif, yaitu mendeskripsikan permasalahan keterbatasan ruang terbuka hijau (RTH) dan pemakaian listrik di perkantoran yang berdampak pada kehidupan lingkungan. Pengumpulan data dengan melakukan survei lapangan sebagai pendukung data-data/dokumentasi lapangan, seperti data kawasan dan tapak terpilih, disertai 
wawancara tidak terstruktur. Selain itu studi literatur mengenai ekologi arsitektur, beyond ecology, Ruang Terbuka Hijau (RTH), kantor sewa dan co-working. Dilanjutkan metode analisis untuk mendapatkan sintesis dan diakhiri kesimpulan. Metode desain yang digunakan berdasarkan standard LEED (Leadership in Energy and Environmental Design). 6 strategi utamanya yaitu: (1) Environment management, mengenai pemanfaatan lingkungan semaksimal mungkin pada tata ruang hijau sebagai faktor ekologi dengan mempertahankan eksisting hijau seperti pohon dan tanaman hias. (2) Energy efficiency, berkaitan dengan renewable energy/energi terbarukan yang memproduksi energi sendiri (energi mandiri) seperti bioo panel/bioo lite dan photovoltaic. (3) Water efficiency, mengenai penggunaan kembali air dan daur ulang air kotor dan air hujan untuk pengairan tanaman. (4) Materials, seperti penggunaan material lokal dan pelingkup ruang dari sisi barat. (5) Waste reduction, pemanfaatan limbah organik yang dapat didaur ulang menjadi pupuk kompos untuk menyuburkan tanaman.

\section{DISKUSI DAN HASIL}

Tapak

Pemilihan kawasan berdasarkan kriteria yang sesuai dengan isu sebelumnya, yaitu kawasan padat bangunan namun belum ada yang menerapkan bangunan ramah lingkungan dan minimnya potensi ruang terbuka hijau. Oleh karena itu, penulis memilih tapak yang berlokasi di Jakarta Barat. Berdasarkan data Badan Pusat Statistik, Jakarta Barat tercatat sebagai salah satu kawasan dengan penggunaan lahan bangunan tertinggi (>80\%) dan potensi RTH terendah $(<20 \%)$.

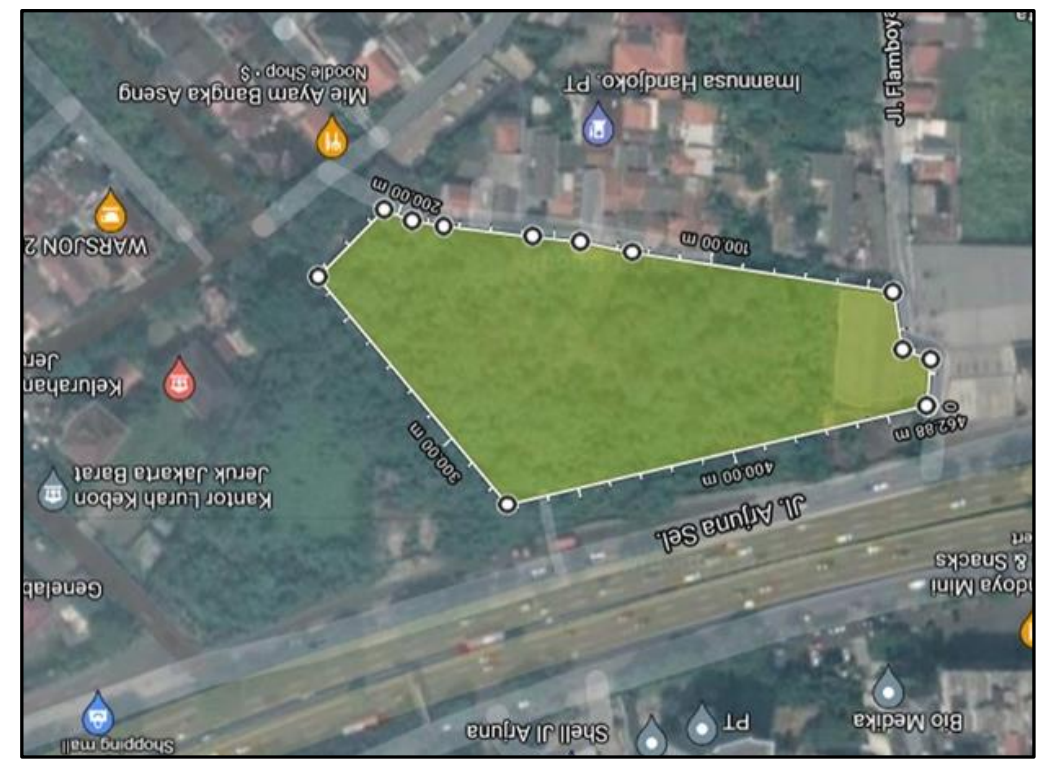

Gambar 1. Tapak Terpilih

Sumber: https://www.google.com/maps/

Tapak berada di depan jalan arteri yaitu Jl. Arjuna Selatan, Kel. Kebon Jeruk, Kec. Kebon Jeruk, Jakarta Barat dengan total luas lahan $9.300 \mathrm{~m}^{2}$. Berdasarkan hasil survei, lokasi tapak mudah terlihat karena berseberangan dengan jalan tol Jakarta-Merak sehingga cukup strategis untuk kegiatan perkantoran, komersial dan industrial. 


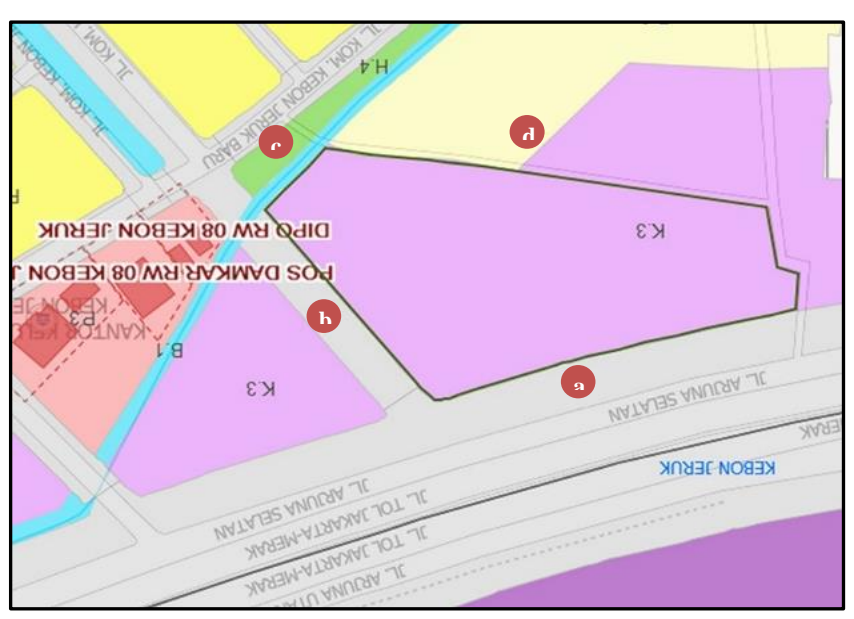

Gambar 2. Rencana Tata Ruang Wilayah (RTRW)

Sumber: https://jakartasatu.jakarta.go.id/

Berdasarkan RTRW (Rencana Tata Ruang Wilayah) DKI Jakarta, tapak ini berada pada zonasi K.3 yaitu zona perkantoran KDB rendah dengan KDB: 30\%, KLB: 1.6, KB: 8, KDH: 45\%, KTB: 40. Batasan tapak: a) Batas utara (Jl. Arjuna Selatan). b) Batas timur (Jl. Kom. Kebon Jeruk Baru (rencana jalan)). c) Batas selatan (sungai drainase (zona terbuka biru)). d) Batas barat (Gg. Mushola dan Jl. Flamboyan Terusan).
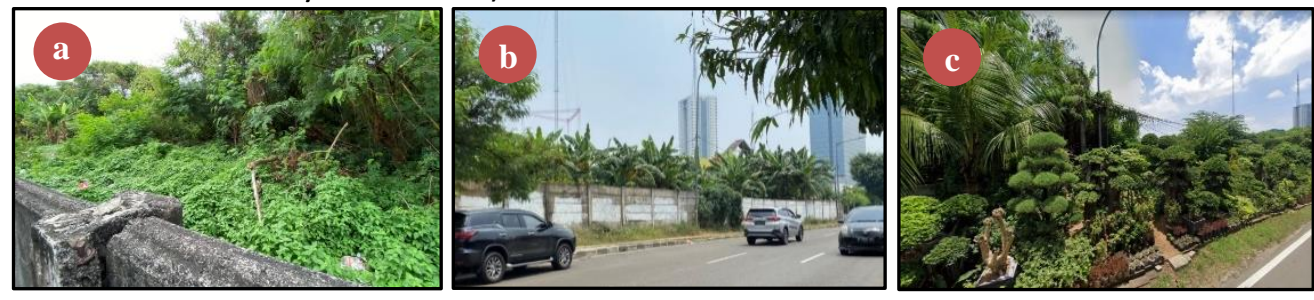

Gambar 3. Kondisi eksisting tapak: a) Lahan kosong. b) Vegetasi pepohonan

c) Penjual tanaman hias di sepanjang jalan Sumber: Penulis, 2021

Berdasarkan hasil survei, kondisi tapak merupakan lahan kosong yang ditumbuhi ilalang dan pepohonan yang akan dipertahankan sebagai vegetasi pada RTH proyek serta sebagai pelestarian, sedangkan pengelola proyek akan bernegosiasi dengan penjual tanaman hias di depan untuk mengurus dan merawat tanaman hias yang dipindahkan untuk landscape proyek.

\section{Analisis Pengguna}

Target pengguna pada proyek ini yaitu warga Jakarta Barat hingga DKI Jakarta karena merupakan ibu kota dengan banyaknya pendatang untuk bekerja, yang terdiri dari kategori masyarakat sesuai dengan umur dan profesi yaitu Generasi Y (milenial usia 25-40 tahun) dan Generasi Z (igeneration usia 18-24 tahun), freelance job, bisnis start-up, tenaga kerja industri (15 tahun keatas).

\section{Program Proyek}

Dalam mendesain perkantoran perlu mengetahui ruang-ruang dan fasilitas apa saja yang dibutuhkan untuk memberikan kenyamanan penggunanya serta adanya upaya perbaikan lingkungan, dengan demikian dibutuhkan program seperti:

Program Utama

a. Mixed Office - Kantor Sewa dan Co-working

Dengan metode LEED serta pendekatan ekologi dan efisiensi energi agar tercipta kelistrikan yang lebih efisien, memperbanyak ruang terbuka hijau di area kantor sebagai resapan dan 
membantu meningkatkan kualitas lingkungan. Adanya photovoltaic pada atap bangunan service. Fasilitas: Coffeeshop, minimarket, foodcourt, fitness center, toko buku dan alat tulis, fun games area, ATM.

b. Ruang Terbuka Hijau (RTH) - Renewable Energy Park (Taman Energi Terbarukan)

Mengoptimalisasi RTH dengan adanya taman energi terbarukan sebagai pelestarian ruang hijau. Disebut taman energi terbarukan karena merupakan sarana pendukung kelistrikan dari hasil fotosintesis tanaman hias daun hijau, yaitu bioenergy seperti bioo lite/bioo panel. Fasilitas: Bioo panel garden, kolam irigasi, area pohon.

\section{Program Penunjang}

a. Interaction Park (Taman Interaksi)

Untuk karyawan kantor dengan memberikan fasilitas pendukung exercise/berolahraga. Taman ini menjadi interaksi antara karyawan dengan lingkungan sekitar (taman). Hal ini menjadikan karyawan dapat merasakan kenikmatan taman dan memiliki ruang gerak aktivitas fisik agar bekerja jauh lebih sehat, berkualitas dan produktif. Fasilitas: Jogging track dan lapangan basket.

b. Pengolahan Sampah Organik - Compost House (Rumah Kompos)

Compost house sebagai area pengelolaan limbah organik menjadi pupuk kompos untuk menyuburkan tanah kebun dan sistem $3 R$ pada sampah organik.

\section{Kebutuhan Ruang}

Dari kelompok pengguna dan program diperoleh kebutuhan ruang sebagai acuan dasar dalam perancangan. Kebutuhan ruang pada proyek ini terdiri dari Area Kantor dan Fasilitas Komersial, Ruang Terbuka Hijau dan Taman Interaksi, Pengelola, Pengolahan Sampah, Area Servis dan Parkir.

Tabel 1. Program Ruang

\begin{tabular}{|c|c|c|c|}
\hline Fungsi & Kebutuhan Ruang & Kelompok & Luas $\left(m^{2}\right)$ \\
\hline $\begin{array}{c}\text { Mixed Office } \\
\text { (Kantor sewa dan co-working) }\end{array}$ & \multirow{5}{*}{ Lantai dasar } & \multirow{5}{*}{$\begin{array}{l}\text { Building } \\
\text { area }\end{array}$} & 844 \\
\hline $\begin{array}{c}\text { Fasilitas komersial } \\
\text { (Minimarket, coffeeshop, ATM) }\end{array}$ & & & 844 \\
\hline Outdoor working space & & & 80 \\
\hline $\begin{array}{c}\text { Area service dan } \\
\text { pengolahan kompos }\end{array}$ & & & 325 \\
\hline R. Ganti lapangan basket & & & 34 \\
\hline \multirow{2}{*}{$\begin{array}{c}\text { Renewable energy park dan } \\
\text { garden area }\end{array}$} & Bioo panel garden (taman aktif) & \multirow{3}{*}{$\begin{array}{l}\text { Green } \\
\text { area }\end{array}$} & 606 \\
\hline & Area taman pasif & & 3320 \\
\hline Sport area & Lapangan basket & & 340 \\
\hline Area parkir & $\begin{array}{l}\text { Shelter sepeda, motor, } \\
\text { mobil, service }\end{array}$ & $\begin{array}{l}\text { Parking } \\
\text { area }\end{array}$ & 2257 \\
\hline
\end{tabular}

\begin{tabular}{|c|c|}
\hline Pengelompokan & Total Luas $\left(\mathbf{m}^{\mathbf{2}}\right)$ \\
\hline Building area & 2.127 \\
\hline Green area & 4.266 \\
\hline
\end{tabular}

\begin{tabular}{|l|l|}
\hline Informasi & Total Luas $\left(\mathbf{m}^{\mathbf{2}}\right)$ \\
\hline Luas Tapak & 9.300 \\
\hline KDB 30\% & 2.790 \\
\hline KLB 1,6 & 14.880 \\
\hline KDH 45\% & 4.185 \\
\hline
\end{tabular}

Sumber: Penulis, 2021

\section{Konsep dan Bentuk Perancangan}

Konsep dasar dari perancangan proyek ini sebagai solusi dari isu yang diangkat, yaitu bagaimana mendesain sebuah mixed office (kantor sewa dan co-working) yang memanfaatkan pembangunan untuk kebutuhan hidup manusia dan lingkungan sekitar demi keseimbangan 
kedua belah pihak (balance) dan efisiensi energi (efficient) dengan pemanfaatan lingkungan sebagai energi terbarukan melalui desain arsitektur ekologi.

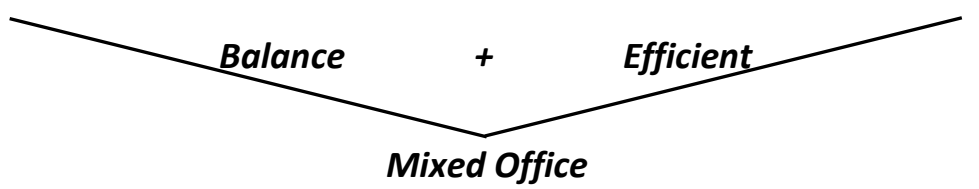

Gambar 4. Skema Konsep Perancangan

Sumber: Penulis, 2021

Proyek ini mengutamakan fungsi bangunan sebagai perkantoran, dimana akan lebih optimal bila didesain dengan bentuk massa persegi dengan pola memanjang. Beberapa pertimbangan pemilihan bentuk massa yang memanjang agar menyesuaikan dengan pola tapak yaitu memanjang ke arah barat dan selatan. Lalu orientasi bangunan lebih jelas, efisiensi ruang dan struktur lebih mudah. Dari segi ekonomi bangunan bentuk persegi panjang akan lebih hemat.

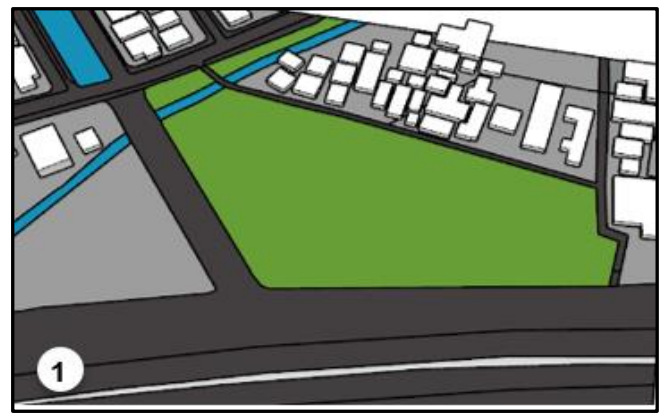

Bentuk pola tapak

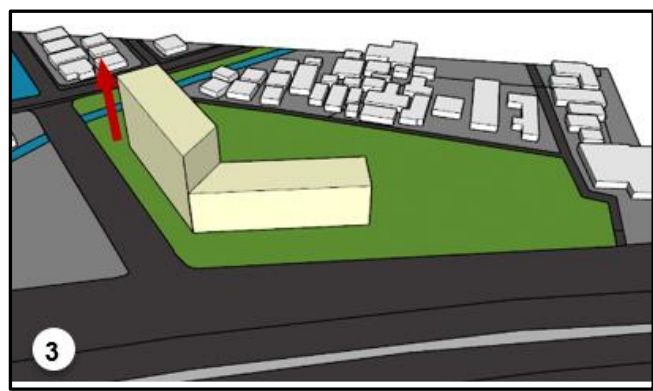

Massa untuk fungsi kantor dinaikan menjadi 8 lantai untuk menyesuaikan kebutuhan ruang dan peraturan $\mathrm{KB}$, massa yang lebih rendah sebagai fungsi komersial (publik).

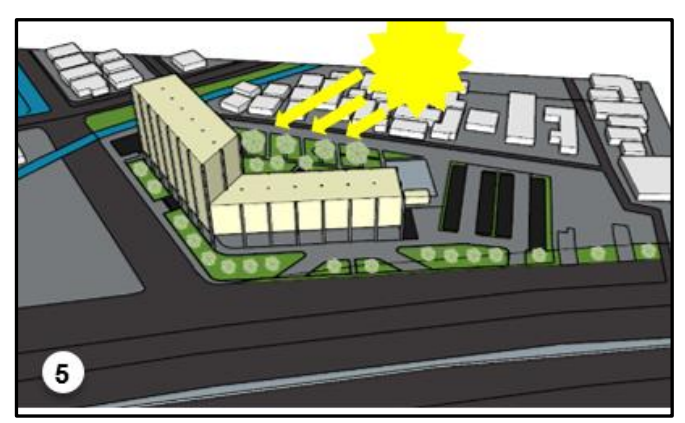

Area Ruang terbuka Hijau secara keseluruhan berada di belakang tapak. Massa yang memanjang ke arah barat dan selatan karena faktor ekologi yaitu agar tanaman di belakang tidak terkena bayangan dari bangunan sehingga tanaman tetap mendapat sinar matahari.

Gambar 5. Proses Gubahan Massa

Sumber: Penulis, 2021

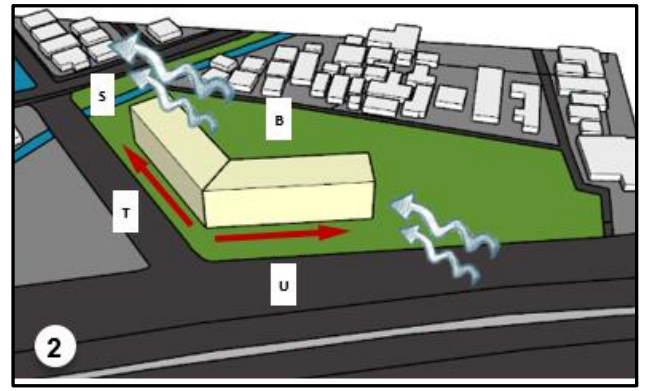

Massa dibuat persegi panjang mengikuti pola tapak yang memanjang ke arah barat dan selatan. Menjadi strategi utama untuk memaksimalkan pencahayaan alami dengan massa yang tipis, karena mendapatkan penerangan secara optimal dan sirkulasi udara yang baik.

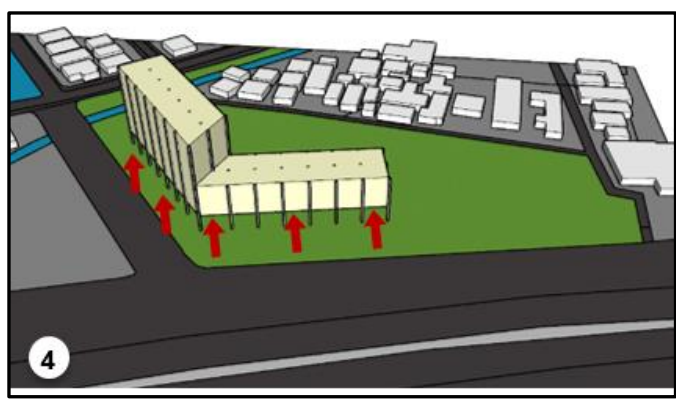

Massa pada lantai dasar dinaikan sehingga mejadi area semi outdoor untuk memaksimalkan udara dan cahaya alami. Selain itu agar taman dibelakang bangunan dapat langsung terekspose dari kejauhan.

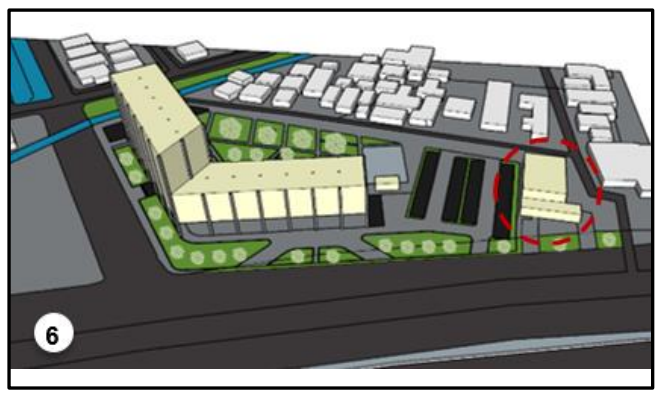

Area pengelola, servis dan pengolahan sampah organik ditempatkan berjauhan dengan bangunan utama. Area parkir sebagai pemisah antara bangunan utama dan bangunan servis. 


\section{Deskripsi Proyek}

Proyek ini dibangun berdasarkan permasalahan yang ada di Jakarta Barat sebagai salah satu wilayah yang paling minim ruang terbuka hijau (RTH) dan lahan pembangunan terpadat kedua setelah Jakarta Pusat, ditambah lagi tidak memperhitungkan pemakaian listrik atau lebih tepatnya pembangunan belum menerapkan konsep ramah lingkungan.

Proyek dibangun dengan tolak ukur perancangan yang mampu mendesain bangunan seimbang dengan lingkungan (balance) agar memberikan kontribusi positif pada perbaikan lingkungan dan pemenuhan kebutuhan energi listrik dapat terpenuhi secara efisien (efficient) serta berkelanjutan.

\section{Strategi Desain}

Pada strategi desain ini merupakan perancangan dengan pengembangan dari metode desain LEED standard dengan pendekatan ecosystem environment dan energy efficiency yang akan diterapkan pada proyek. Berikut beberapa strategi desain serta penerapannya dalam proyek, yaitu:

Tabel 2. Strategi Desain

\begin{tabular}{ll}
\hline \multicolumn{2}{c}{ Strategi } \\
$\begin{array}{ll}\text { Pemanfaatan lingkungan semaksimal } \\
\text { mungkin pada tata ruang hijau sebagai } \\
\text { faktor ekologi }\end{array}$ & $\begin{array}{l}\text { Mempertahankan beberapa eksisting pohon serta } \\
\text { penanaman jumlah pohon, dan tanaman hias untuk bioo } \\
\text { panel garden. }\end{array}$ \\
\hline $\begin{array}{l}\text { Efisiensi energi, yaitu energi terbarukan } \\
\text { sebagai produksi energi listrik yang lebih } \\
\text { efisien }\end{array}$ & $\begin{array}{l}\text { Bioo panel garden untuk kebutuhan kelistrikan outdoor } \\
\text { working space dan photovoltaic untuk kelistrikan } \\
\text { bangunan service serta lampu taman. }\end{array}$ \\
\hline Efisiensi air, penggunaan kembali air & $\begin{array}{l}\text { Pengolahan air dengan sistem grey water treatment dan } \\
\text { rainwater harvest untuk mengairi bioo panel garden. }\end{array}$ \\
\hline $\begin{array}{l}\text { Penggunaan material lokal dan pelingkup } \\
\text { ruang }\end{array}$ & $\begin{array}{l}\text { Penggunaan batu bata, kayu lokal bersertifikasi legal, } \\
\text { balkon bioo panel garden pada sisi barat. }\end{array}$ \\
\hline Pengolahan sampah organik & $\begin{array}{l}\text { Sistem 3R pada sampah organik yang didaur ulang } \\
\text { menjadi pupuk kompos untuk menyuburkan tanah } \\
\text { kebun. }\end{array}$ \\
\hline
\end{tabular}

Sumber: Penulis, 2021

\section{Zonasi Tapak dan Zonasi Vertikal}

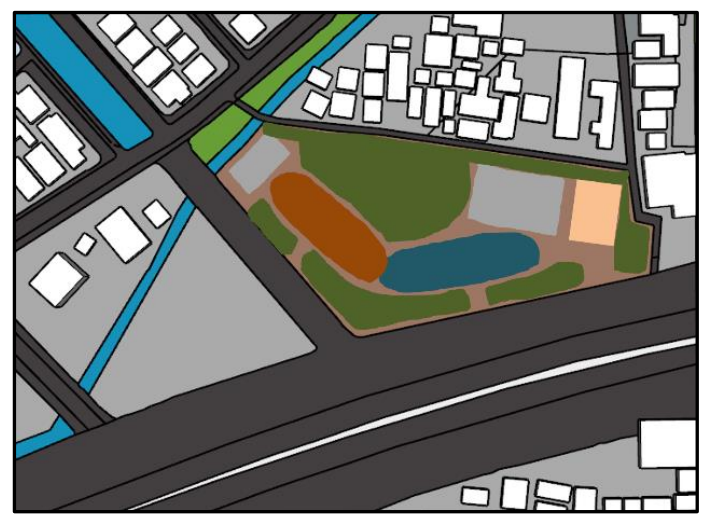

Area hijau (pohon dan

Publik

Semi Privat
Service dan compost house

Parkir

Gambar 6. Zoning Tapak

Sumber: Penulis, 2021 
Seperti halnya metode LEED, pemanfaatan area hijau dimanfaatkan semaksimal mungkin sebagai faktor ekologi dengan mempertahankan eksisting hijau seperti pohon dan tanaman hias. Penempatan area publik memungkinkan view dari luar tapak ke bangunan terlihat jelas dan terdapat entrance bangunan untuk memudahkan masyarakat sekitar untuk berkunjung. Area semi privat dibuat menjauh dari sumber kebisingan jalan raya. Area servis dan pengolahan sampah disatukan untuk memudahkan penyortiran sampah dan dijauhkan dari pandangan pengunjung, area ini akan dikelilingi vegetasi untuk meminimalisir adanya bau dari compost house.

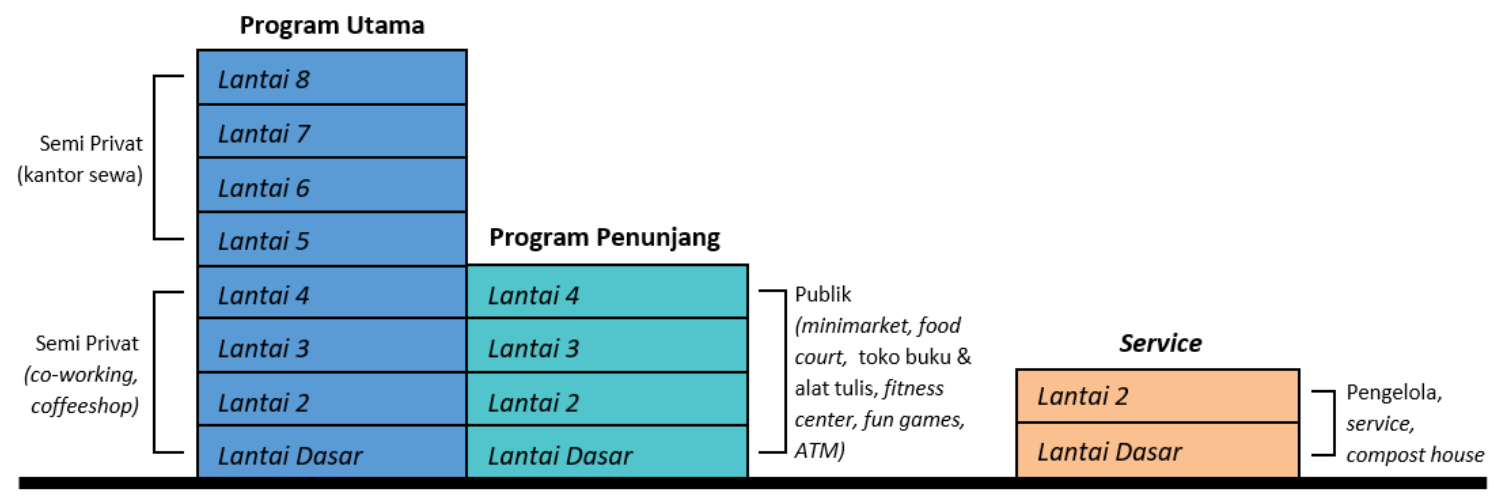

Gambar 7. Zoning Vertikal

Sumber: Penulis, 2021

\section{Deskripsi Mixed Office (Kantor Sewa dan Co-working)}

Kantor co-working berada di It. dasar - It. 4, sistem sewa member berbayar perjam, harian, mingguan dan bulanan dengan pembagian jenis ruang sebagai berikut:

a. Private desk. Terdapat 4 ruangan untuk member yang ingin bekerja secara individu/butuh fokus. Area ini bersifat sementara dan dapat ditempati oleh siapa saja. Dilengkapi loker pada masing-masing meja.

b. Shared desk. Sistemnya dapat ditempati oleh siapa saja, tidak ada aturan dalam penempatannya. Kapasitas mulai dari 1-6 member. Terdapat locker room yang terpisah untuk member shared desk.

c. Dedicated desk. Sistemnya booking, karena meja menjadi 'milik' member selama jangka waktu sewa berjalan.

d. Incubator private team. Kapasitas 4-8 orang, cocok untuk pekerja start-up yang ingin bekerja secara privat dalam 1 team dengan jangka waktu tertentu. Tersedia loker dimeja.

e. Glass board table. Meja kerja yang terbuat dari kaca. Tujuannya agar dapat ditulis/coret oleh pekerja. Dilengkapi spidol untuk mencoret diatas meja lalu dapat dihapus setelah selesai menggunakannya.

f. Ruang rapat informal. Atau "relaxing meeting space", untuk freelance yang ingin meeting dengan client secara nonformal.

Kantor sewa berada di It. 5 sampai It. 8 dengan sistem sewa ruang areal terbuka (open area tenant) tergantung besar/kecil kebutuhan penyewa, pembagian tipe ruang sebagai berikut: 
Tabel 3. Tipe Ruang Kantor Sewa
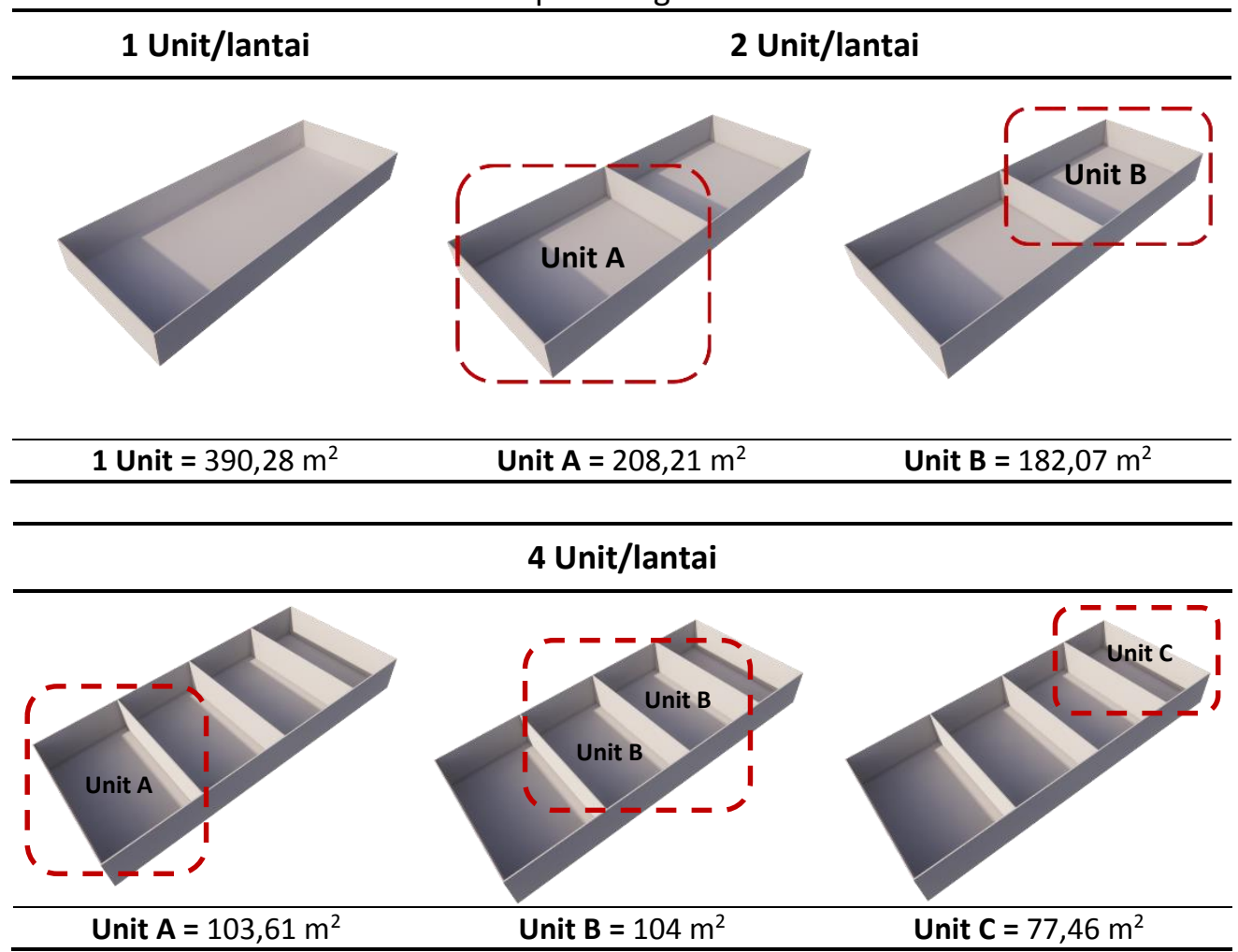

Sumber: Penulis, 2021

\section{Deskripsi Renewable Energy Park (Taman Energi Terbarukan)}

Taman energi terbarukan terdiri dari bioo panel garden dengan kolam khusus irigasi. Peletakan bioo panel garden berdekatan dengan water fountain yang dilengkapi rain water harvest untuk penyimpanan air hujan dan grey water treatment pengolahan air bekas wastafel sebagai sumber pengairan pada bioo panel garden. Selain itu sumber air juga dari PDAM.

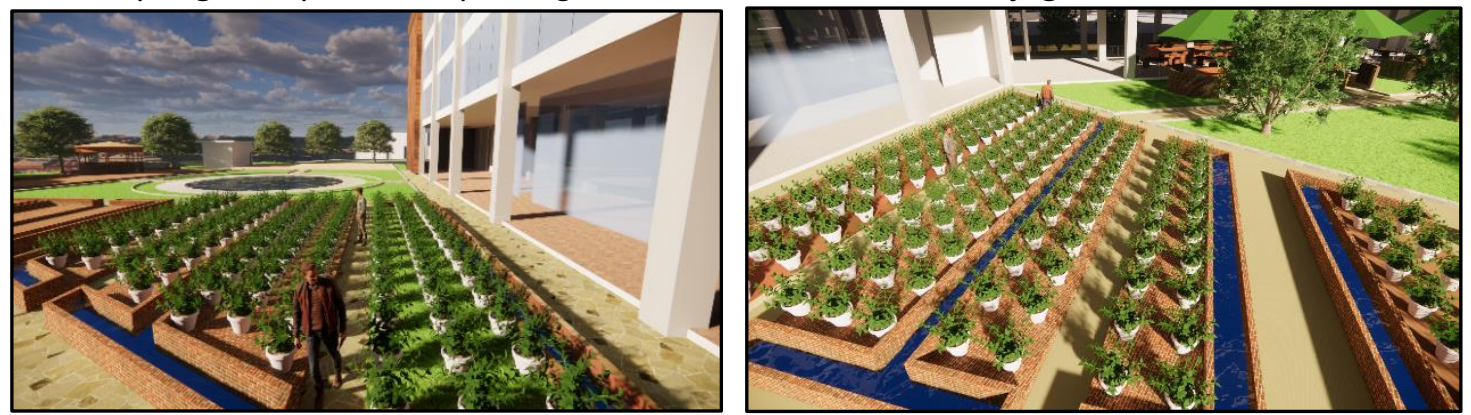

Gambar 8. Bioo Panel Garden dan Kolam Irigasi

Sumber: Penulis, 2021

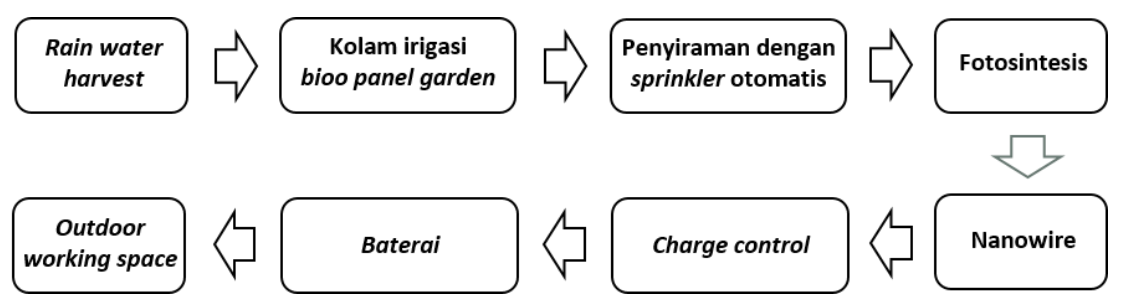

Gambar 9. Diagram Proses Kelistrikan Bioo Panel Garden Sumber: Penulis, 2021 
Bioo panel garden dimanfaatkan sebagai kebutuhan kelistrikan pada outdoor working space, yaitu handphone dan laptop. Proses energi listrik dari bioo panel garden yaitu air disupply dari rain water harvest atau dengan greywater treatment atau PDAM, lalu dipompa ke kolam irigasi. Setelah itu air dipompa menuju sprinkler otomatis untuk penyiraman bioo panel garden. Selanjutnya tanaman akan berfotosintesis mengubah $\mathrm{CO} 2$ dan $\mathrm{H} 2 \mathrm{O}$ menjadi $\mathrm{O} 2$ dan senyawa organik. Senyawa organik dipecah oleh mikroogganisme didalam pot. Elektron yang terlepas menuju nanowire yang telah disediakan. Lalu ke charge control untuk mengatur listrik yang akan masuk ke baterai. Setelah itu listrik disimpan di baterai dan dialirkan ke outdoor working space.

\section{Interaction Park (Taman Interaksi)}

Taman interaksi ini merupakan fasilitas pendukung bagi pekerja kantor sebagai area exercise/berolahraga. Taman ini menjadi interaksi antara karyawan dengan lingkungan sekitar (taman) dan interaksi sosial antar pekerja. Fasilitas: Jogging track dan lapangan basket. Jogging track akan mengitari hampir keseluruhan dari area tapak, sehingga pekerja dapat merasakan kesejukan taman secara optimal dan memiliki ruang gerak aktivitas fisik agar bekerja jauh lebih sehat, berkualitas dan produktif.
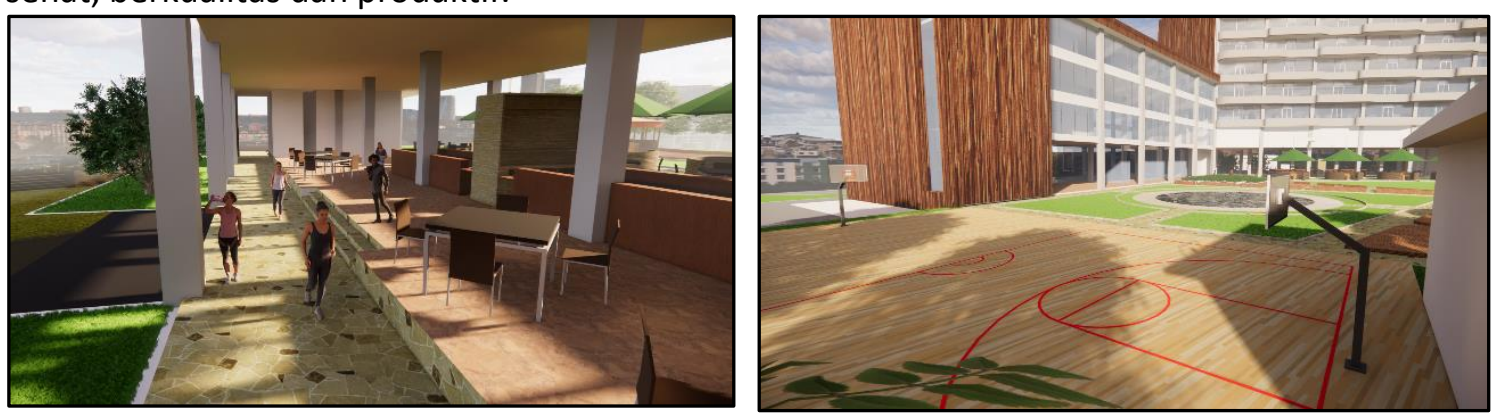

Gambar 10. Jogging Track (kiri) dan Lapangan Basket (kanan) Sumber: Penulis, 2021

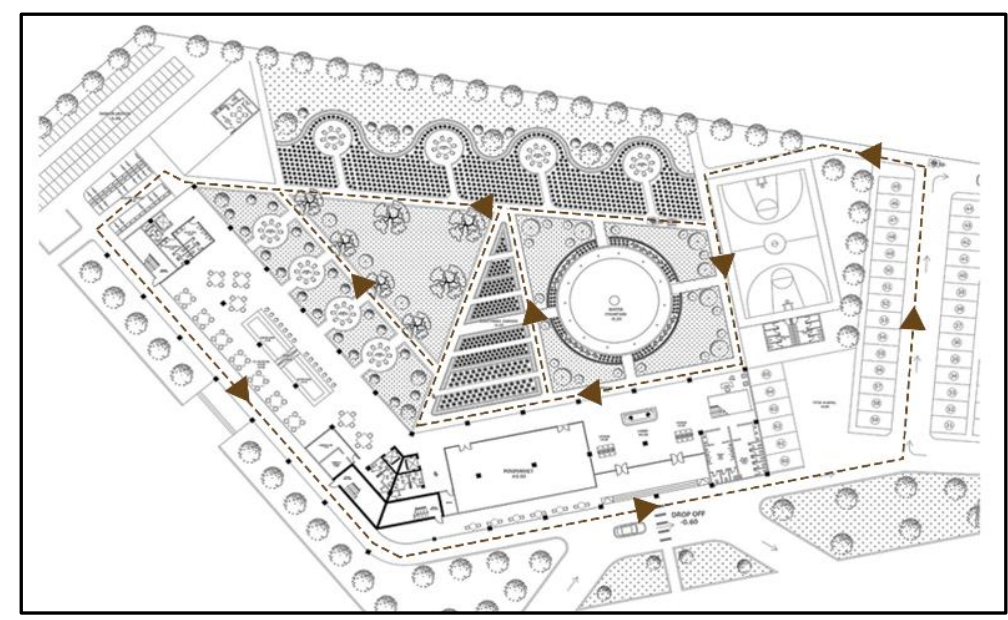

Gambar 11. Jalur Pergerakan Jogging Track Sumber: Penulis, 2021

\section{Deskripsi Pengolahan Sampah organik (Compost House)}

Compost house sebagai area memproses pengomposan dari limbah organik seperti limbah C (coklat) yaitu daun dan ranting kering (limbah pohon), tissue, kertas, kardus (produk-produk berbahan dasar kayu dari limbah kantor dan fasilitasnya) serta limbah N (hijau) yaitu sisa-sisa makanan dari food court. Pengomposan ini dilakukan untuk menyuburkan tanah kebun dan sistem $3 R$ pada sampah organik. 


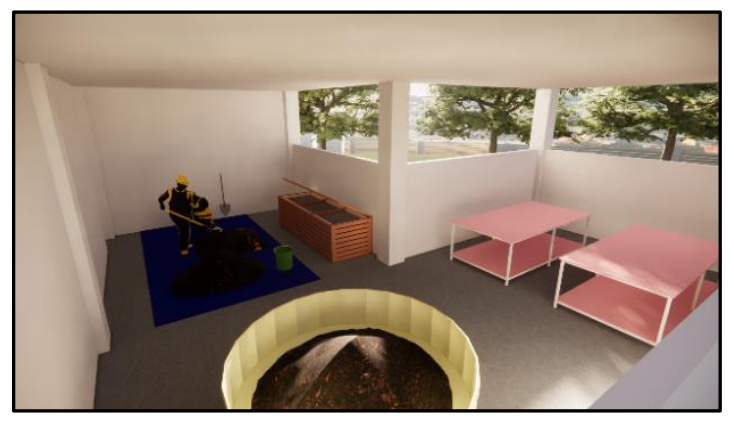

Gambar 12. Compost House

Sumber: Penulis, 2021

\section{Pemakaian Photovoltaic (PV)}

Pada atap bangunan compost, service dan kantor pengelola terdapat photovoltaic (PV) sebagai pemanfaatan panas dari sinar matahari menjadi listrik dengan aplikasi panel surya. Digunakan sebagai kelistrikan bangunan compost, service dan kantor pengelola serta kebutuhan lampu taman dan area parkir.

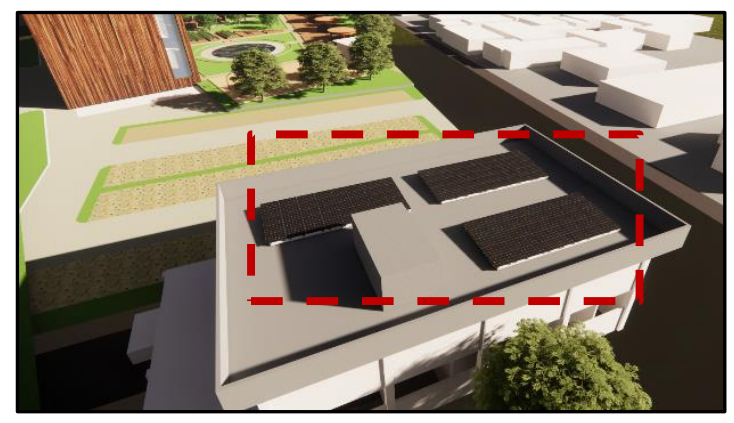

Gambar 13. Photovoltaic pada Atap Bangunan Compost, Service dan Pengelola Sumber: Penulis, 2021

\section{KESIMPULAN DAN SARAN}

\section{Kesimpulan}

Proyek yang bertemakan 'beyond ecology' ini, dibangun berdasarkan permasalahan yang ada di Jakarta Barat sebagai wilayah dengan keterbatasan Ruang Terbuka Hijau (RTH) dan pemakaian listrik perkantoran yang umumnya terjadi karena meningkatnya kebutuhan ruang usaha di dunia bisnis dan industri kreatif (start-up). Adapun proyek ini untuk mengajukan suatu rancangan pembangunan kantor sewa dan co-working dengan pemanfaatan taman energi terbarukan dengan maksud menciptakan kelistrikan yang lebih efisien serta perwujudan ruang terbuka hijau yang mendominasi dari luas keseluruhan tapak sebagai ciri bangunan ekologis.

Proyek ini diharapkan menjadi gagasan baru ibukota khususnya Jakarta Barat untuk beralih menuju rancangan kantor yang lebih memperhatikan kepedulian terhadap lingkungan dalam memberi kontribusi perbaikan lingkungan.

\section{Saran}

Perancangan ini perlu dilakukan penelitian secara lebih lagi agar dapat dikembangkan secara lebih lanjut, dengan penggunaan tema yang sama dan penerapan yang lebih sempurna dari segi analisis dan desain yang berkelanjutan.

Sebaiknya dalam perancangan perkantoran pada saat ini perlu memperhatikan aspek lingkungan dan hemat energi dalam memberikan kontribusi positif pada perbaikan lingkungan serta meningkatkan kenyamanan bagi penggunanya. 


\section{REFERENSI}

Alam, K. P. P. (2021). Ekologi, Ekologi Manusia dan Lingkugan Hidup, diunduh 18 Juli 2021, $<$ https://onlinelearning.uhamka.ac.id/mod/forum/discuss.php?d=8

Anditriplea. Sistem Penyewaan Kantor Sewa, diunduh 18 Juli 2021, <http://anditriplea.blogspot.com/2011/06/sistem-penyewaan-kantor-sewa.html

Atenda. (2020). Kelebihan dan Kekurangan Coworking Space, diunduh 3 Juni 2021, $<$ https://www.atenda.id/berita/Kelebihan-dan-Kekurangan-Coworking-Space/85

Badan Pusat Statistik. (2020). Provinsi DKI Jakarta dalam Angka: 2020. Jakarta: BPS Provinsi DKI Jakarta

Fahmi, Y. (2020). Pentingnya Ruang Terbuka Hijau untuk Warga Perkotaan Seperti Jakarta, diunduh 2 Juni 2021, <https://www.liputan6.com/news/read/4374029/pentingnyaruang-terbuka-hijau-untuk-warga-perkotaan-seperti-jakarta

Frick, H. (1998). Dasar-dasar Arsitektur Ekologis. Yogyakarta: Kanisius

Jakarta Green Building. (2018). Eksistensi Green Building di Kota Jakarta, diunduh 20 Juli 2021, $<$ https://greenbuilding.jakarta.go.id/news/2018/02/20/eksistensi-green-building-dikota-jakarta/

Marlina, E. (2008). Panduan Perancangan Bangunan Komersial. Yogyakarta: Andi

Metallinou, V. A. (2006). Ecological Propriety and Architecture 86, 15-22

Prabowo, K. W. (2020). Jakarta Krisis Ruang Terbuka Hijau, diunduh 3 Juni 2021, <https://www.medcom.id/nasional/metro/nbwQp33K-jakarta-krisis-ruang-terbuka-hijau

Priskila, M. (2019). Ruang Terbuka Hijau: Pengertian, Manfaat, Jenis, dan Penyediaan, diunduh 3 Juni 2021, <https://foresteract.com/ruang-terbuka-hijau/

Setiawan, S. (2021). Pengertian Kantor - Tujuan, Fungsi, Unsur, Ciri, Jenis, Modern, Tata Ruang, diunduh 8 Juni 2021, <https://www.gurupendidikan.co.id/pengertian-kantor/

Sutanto, A. (2021). Virtual Seminar Stupa 8.31: Kuliah Dromologi Spatial

Undang-Undang No. 2 Tahun 2007 tentang Penataan Ruang

Winata, S. (2021). Virtual Seminar Stupa 8.31: Eco Logic 
